\title{
PENGARUH GAYA KEPEMIMPINAN TRANSFORMASIONAL, PELATIHAN TERHADAP MOTIVASI KERJA SERTA IMPLIKASI KINERJA TENAGA KEPENDIDIKAN DI UNIVERSITAS MERCU BUANA JAKARTA
}

\author{
Paijan dan Hapzi Ali \\ Universias Mercu Buana Jakarta \\ Email: paijan.tupasca@gmail.com dan hapzi.ali@gmail.com
}

\begin{abstract}
This study aims to determine the effect of transformational leadership style and training on motivation and its implications on the performance of both partially and simultaneously. Data collected through survey method and instrument questioner analysis to be distributed to the units of Mercu Buana University academic staff of 126 educators. Research analysis method is descriptive method and quantitative verification tool path analysis (path analysis) was then forwarded to the analysis of determination (R2), partial hypothesis test ( $\mathrm{t}$ test) and test hypotheses simultaneously ( $\mathrm{F}$ test). Prior to the analysis process has been tested intrument with validity and reliability. Results of this study were: 1) the transformational leadership style has no effect on work motivation of educators in Mercu Buana University; 2) Training effect on work motivation of educators in Mercu Buana University; 3) transformational leadership style and training of education personnel motivation to work directly and indirectly in Mercu Buana University; 4) transformational leadership style of the performance of educators at Mercu Buana University; 5) Training of educational personnel in the performance of Mercu Buana University; 6) transformational leadership style and training of education personnel performance both directly and indirectly in Mercu Buana University; 7) To analyze the effect of motivation on the performance of work at the University of Mercu Buana.
\end{abstract}

Keywords: transformational leadership style, coaching, motivation and performance of educators.

Abstrak: Penelitian ini bertujuan untuk mengetahui pengaruh gaya kepemimpinan transformasional dan pelatihan terhadap motivasi dan implikasinya terhadap kinerja baik secara parsial maupun secara simultan. Pengumpulan data dilakukan melalui metode survei dengan populasi seluruh tenaga kependidikan sejumlah 305 orang, sedangkan sampel sejumlah 126 orang dengan teknik sample random sampling. Metode analisis deskriptif dan verifikatif kuantitatif dengan analisis jalur (Path Analysis) diteruskan dengan analisis determinasi $\left(\mathrm{R}^{2}\right)$, uji hipotesis secara parsial (uji t) dan uji hipotesis secara simultan (uji F). Sebelum dilakukan proses analisis telah dilakukan uji intrument dengan validitas dan reabilitas. Hasil penelitian: 1) Gaya kepemimpinan transformasional tidak berpengaruh terhadap motivasi kerja tenaga kependidikan di Universitas Mercu Buana; 2) Pelatihan berpengaruh terhadap motivasi kerja tenaga kependidikan di Universitas Mercu Buana; 3) Gaya kepemimpinan transformasional dan pelatihan terhadap motivasi kerja tenaga kependidikan baik langsung dan tidak langsung di Universitas Mercu Buana; 4) Gaya kepemimpinan transformasional terhadap kinerja tenaga kependidikan di Universitas Mercu Buana; 5) Pelatihan terhadap kinerja tenaga kependidikan di Universitas Mercu Buana; 6) Gaya 
kepemimpinan transformasional dan pelatihan terhadap kinerja tenaga kependidikan baik langsung dan tidak langsung di Universitas Mercu Buana; 7) Untuk menganalisis pengaruh motivasi kerja terhadap kinerja di Universitas Mercu Buana.

Kata Kunci: Gaya kepemimpinan transformasional, pelatihan, motivasi dan kinerja tenaga kependidikan.

\section{PENDAHULUAN}

Dalam setiap organisasi akan selalu berusaha meningkatkan kinerja karyawannya demi tercapainya tujuan organisasi. Kepemimpinan merupakan salah satu isu dalam menajemen yang masih cukup menarik untuk diperbincangkan hingga dewasa ini. Pemimpin senantiasa melakukan pembinaan terhadap karyawan agar dapat memberikan kepuasan dan komitmen organisasi.

Peningkatan pengetahuan, skill, perubahan sikap, prilaku, koreksi terhadap kekurangan-kekurangan kinerja dibutuhkan untuk meningkatkan kinerja dan produktifitas melalui pelatihan sehingga pegawai merasa termotivasi, karena memiliki kemampuan dan keahlian dalam melaksanakan pekerjaan-pekerjaannya dan merasakan adanya peningkatan kemampuan didiri mereka.

Permasalahan yang dihadapi oleh beberapa lembaga pendidikan khususnya di Universitas Mercu Buana adalah masalah pengelolaan dan pengembangan sumber daya manusia khususnya dalam peningkatan motivasi kerja, dimana motivasi kerja karyawan merupakan hal yang sangat penting untuk mendorong karyawan dalam meningkatkan kemampuan di bidangnya, oleh karena itu untuk dapat meningkatkan motivasi kerja karyawan diperlukan suatu gaya kepemimpinan tertentu dan sistem pelatihan yang efektif.

Berikut data hasil penilaian kinerja karyawan Universitas Mercu Buana yang dapat dilihat pada Tabel 1 berikut :

Tabel 1. Penilaian Kinerja Tenaga Kependidikan Universitas Mercu Buana Dari Tahun 2011 s.d 2014

\begin{tabular}{ccccccc}
\hline Tahun & Istimewa & $\begin{array}{c}\text { Sangat } \\
\text { Baik }\end{array}$ & $\begin{array}{c}\text { Penilaian } \\
\text { Baik }\end{array}$ & Cukup & $\begin{array}{c}\text { Kurang } \\
\text { Baik }\end{array}$ & Jumlah \\
\hline 2011 & - & 107 & 74 & 4 & - & 185 \\
2012 & - & 114 & 98 & 8 & & 220 \\
2013 & - & 154 & 83 & 5 & - & 242 \\
2014 & - & 257 & 10 & 7 & - & 274 \\
\hline
\end{tabular}

Sumber : BSDM Tahun 2014.

Dari data penilaian kinerja diatas telah terjadi kenaikan kinerja tenaga kependidikan dari tahun 2011 sebanyak 185 orang sangat baik 107 orang dalam persentasi 58\%, baik sebanyak 74 orang dalam persentasi $40 \%$ dan cukup sebanyak 4 orang dalam persentasi $2 \%$, tahun 2012 sebanyak 220 orang sangat baik 114 orang dengan persentasi 52\%, baik sebanyak 98 orang dengan persentasi $44,5 \%$, dan cukup 4 orang dengan persentasi 3,5\%, tahun 2013 sebanyak 242 orang sangat baik 154 orang dengan persentasi 63,5\%, baik sebanyak 83 orang dengan persentasi $34,5 \%$ dan cukup sebanyak 5 orang dengan persentasi $2 \%$ dan tahun 2014 sebanyak 274 orang sangat baik sebanyak 257 orang dengan 
persentasi $94 \%$, baik sebanyak 10 orang dengan persentasi 3,6\% dan cukup sebanyak 7 orang dengan persentasi $2,4 \%$ sebagaimana tabel 1.2 tersebut diatas. Tujuan penelitian menganalisa pengaruh gaya kepemimpinan transformasional terhadap motivasi kerja tenaga kependidikan di Universitas Mercu Buana; pengaruh pelatihan terhadap motivasi kerja tenaga kependidikan, pengaruh gaya kepemimpinan transformasional dan pelatihan terhadap motivasi kerja tenaga kependidikan baik langsung dan tidak langsung di Universitas Mercu Buana.

\section{KAJIAN TEORI}

Gaya Kepemimpinan Transformasional. Kepemimpinan transformasional, yang mengubah status quo dengan menggugah nilai-nilai pengikut dan pemahaman mereka kepada tujuan yang lebih tinggi. Pimpinan transformasional mengartikulasikan permasalahan mereka dalam sistem yang ada dan memiliki visi luar biasa mengenai bentuk masyarakat atau organisasi baru Hughes, Ginnett, Curpahy, (2012:530). Menurut Burns dalam Hughes,et al, (2012:530), kepemimpinan transformasional pada akhirnya merupakan latihan moral dalam hal meningkatkan standar prilaku manusia.

Faktor yang mempegaruhi gaya kepemimpinan transformasional, yaitu terdiri dari dimensi (1) charisma atau idealism (2) inspirasi atau motivasi (3) stimulasi intelektual (4) pertimbangan individual. Robbin (2007:473). Sedangkan indikator gaya kepemimpinan transformasional yaitu : (1) visi dan misi, menanamkan kebanggaan, meraih penghormatan dan kepercayaan (2) mengkomunikasikan harapan tinggi, menggunakan simbol untuk memfokuskan pada usaha, menggambarkan maksud penting secara sederhana (3) mendorong intelegensi, rasionalitas dan pemecahan masalah secara hati-hati (4) memberikan perhatian pribadi, melayani secara pribadi, melatih dan menasehati, menuurut Stephen P.Robbins, (2007, 473).

Pelatihan. Pelatihan dan pengembangan sumber daya manusia semakin meningkat menjadi masalah strategis utama karena berbagai alasan. Menurut Mello, (2006) dalam Wibowo,(2012;442) mengemukakan bahwa: (1). Perubahan yang cepat dalam teknologi berlanjut menyebabkan meningkatnya tingkat keausan ketrampilan. (2). Desain ulang pekerjaan dalam pekerjaan yang mempunyai tanggun jawab lebih luas memerlukan sumber daya manusia memperkirakan lebih banyak tanggung jawab, melakukan inisiatif, dan pengembangkan lebih lanjut keterampilan interpersonal untuk menjamin kinerja dan keberhasilan mereka. (3). Merger dan akuisisi telah meningkat sengan pesat. Aktivitas ini mengintegrasikan sumber daya manusia dalam satu organisasi ke dalam organisasi lainnya yang mempunyai budaya sangat berbeda. (4). Sumber daya manusia bergerak dari satu pemberi kerja ke pemberi kerja lainnya dengan frekuensi labih besar daripada periode sebelumnya. Dengan loyalitas lebih rendah pada pemberi kerja tertentu dan lebih pada karier sumber daya manusia, lebih banyak waktu harus dikeluarkan dalam mengintegrasikan sumber daya manusia baru ke dalam tempat pekerjaan. (5). Globalisasi operasi bisnis memerlukan manajer mendapatkan pengetahuan dan keterampilan yang berhubungan dengan perbedaan bahasa dan budaya.

Motivasi Kerja. Sebagian besar orang sulit memotivasi diri sendiri. Karena itu tidak mengherankan bahwa memotivasi orang lain adalah tugas yang sulit dan rumit. Untuk meningkatkan kemungkinan keberhasilan tugas itu, ilmuwan bidang prilaku manusia telah 
berusaha menyediakan bahan supaya kita dapat memperoleh pengertian yang lebih baik mengenai dinamika motivasi. Motivasi merupakan proses psikologis yang membangkitkan dan mengarahkan prilaku pada pencapaian tujuan atau goal-directed behavior. Menurut Robert kreitner dan Angelo Khicki, (2001) dalam Wibowo, (2012:378). Manajer perlu memahami proses prikologis ini apabila mereka ingin berhasil membina pekerja menuju pada penyelesaian sasaran organisasi. Berdasarkan uraian di atas maka dapat disimpulkan bahwa motivasi kerja adalah kelompok pendorong yang berasal baik dari dalam maupun dari luar individu untuk melakukan pekerjaan yang mengarah pada pemenuhan kebutuhankebutuhannya.

Kinerja. Kinerja dapat dipandang sebagai proses maupun hasil pekerjaan. Kinerja merupakan suatu proses tentang bagaimana pekerjaan berlangsung untuk mencapai hasil kerja. Namun hasil itu sendiri juga menunjukkan kinerja.Wibowo (2012:81). Presentasi kerja adalah suatu hasil kerja yang dicapai seseorang dalam menyelesaikan pekerjaan yang dibebankan kepadanya. Kinerja berarti pencapaian prestasi seseorang berkenaan dengan tugas yang diberikan kepadanya. Penilaian atau evaluasi bagi suatu pekerjaan sangat penting, Penilaian kinerja adalah proses melalui mana organisasi-organisasi mengevaluasi dan menilai prestasi kerja karyawan. Kegiatan ini dapat memperbaiki keputusankeputusan personalia dan memberikan umpan balik kepada para pegawai tentang pelaksanaan kerja mereka.

Kerangka Pemikiran. Berdasarkan kajian teori maka teori yang digunakan dalam penelitian ini terutama dalam kerangka berfikir (konstruk) dapat digambarkan sebagai berikut:



Gambar 1. Kerangka Pemikiran

Hipotesis. Dengan demikian dapat ditarik kesimpulan sementara sebagai hipotesis penelitian ini adalah sebagai berikut: (1) Gaya kepemimpinan transformasional berpengaruh terhadap motivasi kerja tenaga kependidikan di Universitas Mercu Buana; (2) Pelatihan berpengaruh terhadap motivasi kerja tenaga kependidikan di Universitas Mercu Buana;(3) Gaya kepemimpinan transformasional dan pelatihan terhadap motivasi kerja tenaga kependidikan baik langsung dan tidak langsung di Universitas Mercu Buana;(4) Gaya kepemimpinan transformasional terhadap kinerja tenaga kependidikan di Universitas Mercu Buana;(5) Pelatihan terhadap kinerja tenaga kependidikan di Universitas Mercu Buana;(6) Gaya kepemimpinan transformasional dan pelatihan terhadap kinerja tenaga 
kependidikan baik langsung dan tidak langsung di Universitas Mercu Buana;(7) Untuk menganalisis pengaruh motivasi kerja terhadap kinerja di Universitas Mercu Buana.

\section{METODE}

Metode penelitian yang digunakan survey dengan membuat angket kepada responden (karyawan) yang akan menjawab pernyataan-pernyataan tentang pengaruh gaya kepemimpinan transformasional dan pelatihan terhadap motivasi kerja dan implikasinya terhadap kinerja tenaga kependidikan di Universitas Mercu Buana Jakarta.

Tingkat eksplanasi (level of explanation) penelitian ini adalah penelitian deskriptif dan verifikatif, dimana penelitian deskriptif adalah menganalisa data dengan untuk memperoleh deskripsi atau gambaran tentang gaya kepemimpinan transformasional dan pelatihan terhadap motivasi kerja dan implikasinya terhadap kinerja tenaga kependidikan di Universitas Mercu Buana Jakarta melalui data sampel sebagaimana adanya, melakukan analisis dan membuat kesimpulan yang berlaku untuk umum pada Universitas Mercu Buana Jakarta. Sedangkan penelitian Verifikatif adalah untuk mengetahui hubungan antar variabel melalui suatu pengujian hipotesis berdasarkan data yang dikumpulkan dilapangan. Selain itu penelitian ini juga merupakan penelitian korelasi dengan menggunakan analisis korelasi Pearson Product Moment.

Jenis dan Sumber Daya yang dipergunakan dalam penelitian ini adalah data primer (diperoleh dengan menggunakan kuesioner atau angket kepada para responden) dan data sekunder yang didapatkan secara tidak langsung, yaitu diperoleh dan dicatat oleh pihak lain. Dalam hal ini dapat berupa catatan, laporan historis, seperti profil perusahaan.

Teknik Pengumpulan Data. Pengumpulan data dalam penelitian ini menggunakan : (a) Data Primer (b) Data Sekunder, dan kuesioner dipilih sebagai metode pengumpulan data dalam penelitian ini.

Teknik Analisis Data. Uji Validitas. Dengan menggunakan rumus teknik korelasi Product Moment, dengan taraf signifikansi sebesar $5 \%$. Kriteria Putusan:

Jika nilai $r$ hitung $>r$ tabel dan Sig. $<0,05$ maka valid

Jika nilai $r$ hitung < r tabel dan Sig. > 0,05 maka tidak valid

Uji Reliabilitas. Pengujian reliabilitas instrument dilakukan dengan menguji skor antar item dengan menggunakan rumus Cronbach Alpha. Untuk mengetahui reliabilitas atau tidaknya suatu instrument pengambilan data dari suatu peneltian dapat dilakukan dengan melihat nilai koefisien reliabilitas (coefficient reliability). Nilai koefisien reliabilitas berkisar antara 0 sampai 1. Apabila nilai koefisien tersebut mendekati 1, maka instrumen tersebut semakin reliabel. Ukurang yang dipakai untuk menunjukkan pernyataan tersebut reliabel, apabila nilai Crombach Alpha di atas 0,6.

Path Analysis. Untuk melakukan analisis data, pengolahan data dilakukan menggunakan analisis jalur (path analysis). Kepuasan kerja diposisikan sebagai variabel intervening yang menghubungkan antara variabel independent dan variabel dependent. Metode path analysis merupakan perluasan dari regresi linier berganda yang digunakan untuk menaksir hubungan kausalitas antara variabel dalam model penelitian yang dibangun berdasarkan landasan teori yang kuat. 
Sesuai dengan kerangka pemikiran maka dapat membuat persamaan structural yaitu persamaan regresi yang menunjukan hubungan yang dihipotesiskan. Persamaan tersebut sebagai berikut:

$$
Y=\operatorname{Pyx}_{1} X_{1}+P x_{2} X_{2}+P y x_{3} X_{3}+\epsilon_{1}
$$

Dimana: $\mathrm{X}_{1}=$ Gaya Kepemimpinan Transformasional; $\mathrm{X}_{2}=$ Pelatihan; $\mathrm{Y}=$ Motivasi Kerja; $\mathrm{Z}=$ Kinerja; $\mathrm{P}=$ Kofisien Korelasi; $\quad=$ Error

Berdasarkan hubungan antar variabel secara teoritis dapat dibuat model dalam bentuk persamaan strukturalnya yang sesuai hipotesis yang diajukan sebagai berikut:

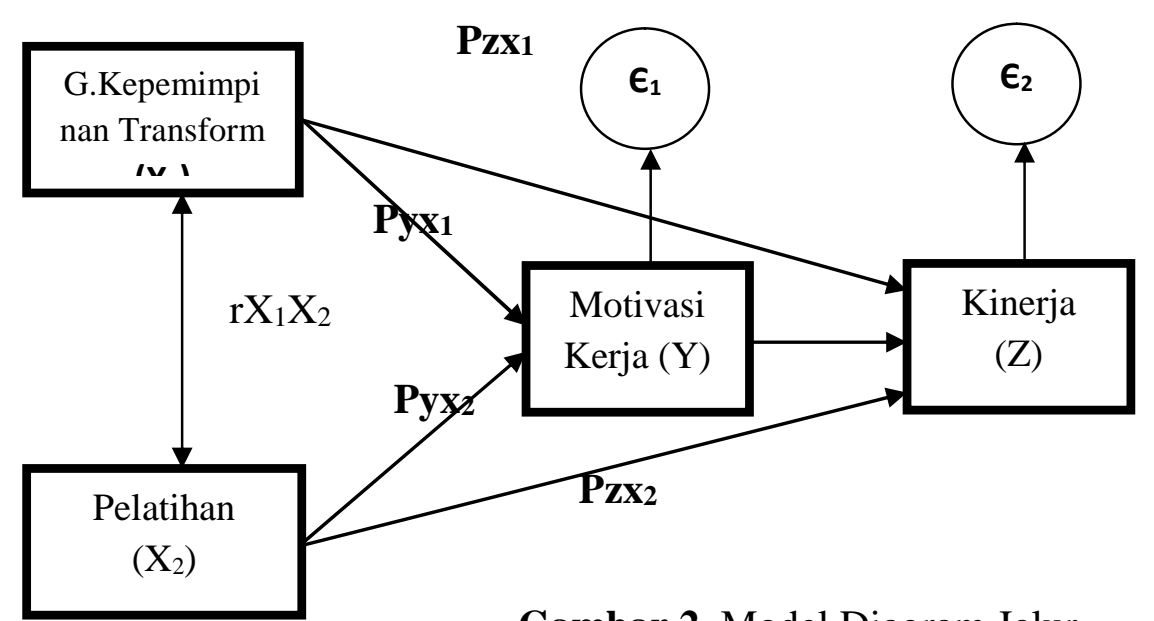

Gambar 2. Model Diagram Jalur

Koefisien Determinasi $\left(\mathbf{R}^{2}\right)$. Dalam analisis korelasi terdapat suatu angka yang disebut dengan koefisien determinasi atau yang sering disebut dengan koefisien penentu, karena besarnya adalah kuadrat dari koefisien korelasi $\left(r^{2}\right)$. Jika $\left(r^{2}\right)=100 \%$ berarti variabel independent berpengaruh sempurna tehadap variabel dependent, demikian sebaliknya jika $r^{2}=0$ berarti variabel independent tidak berpengaruh terhadap variabel dependent.

Uji Parsial (Uji t). Uji-t pada dasarnya menunjukan seberapa jauh pengaruh satu variabel penjelas atau bebas secara individual dalam menerangkan variasi variabel terikat. Ghozali, (2010:97). Pengujian ini bertujuan untuk menguji apakah masing-masing variabel bebas berpengaruh secara signifikan terhadap variabel terikat secara parsial dengan $u=0,05$ dan juga penerimaan atau penolakan hipotesis.

Uji parsial (Uji t) untuk menjawab hipotesis kedua, ketiga, kelima, keenam dan kedelapan. Uji ini digunakan untuk mengetahui pengaruh variabel bebas Gaya Kepemimpinan Transformasional $\left(\mathrm{X}_{1}\right)$, Pelatihan $\left(\mathrm{X}_{2}\right)$ dan Motivasi Kerja $(\mathrm{Y})$ terhadap variabel terikat Kinerja (Z) secara parsial. Pengujian ini dilakukan dengan membandingkan nilai $t_{\text {hitung }}$ dengan $t_{\text {tabel }}$ pada derajat kesalahan 5\%. Apabila nilai $t_{\text {hitung }}>$ $t_{\text {tabel, }}$ maka variabel bebasnya $\left(\mathrm{X}_{1}\right.$ dan $\left.\mathrm{X}_{2}\right)$ serta variabel intervening $(\mathrm{Y})$ masing-masing memberi pengaruh yang signifikan terhadap variabel terikat (Z). Sebaliknya apabila nilai $t_{\text {hitung }}<t_{\text {tabel}}$, maka variabel bebasnya $\left(\mathrm{X}_{1}\right.$ dan $\left.\mathrm{X}_{2}\right)$ serta variabel intervening $(\mathrm{Y})$ masingmasing tidak memberi pengaruh yang signifikan terhadap variabel terikat (Z). Adapun kriteria pengujian pada tingkat signifikansi 0,05 (5\%) sebagai berikut. 
Apabila thitung $>t_{\text {tabel }}$ atau alpha $<0.05$, maka $\mathrm{H}_{1}$ di terima dan $\mathrm{H}_{0}$ di tolak. Apabila $t_{\text {hitung }}<\mathrm{t}_{\text {tabel }}$ atau alpha $>0.05$, maka Ho diterima dan $\mathrm{H} 1$ di tolak.

Uji F (Simultan). Uji F dilakukan untuk melihat apakah model regresi dapat digunakan untuk memprediksi variabel dependen. Tingkat probabilitas $<0,05$ dianggap signifikan atau model regresi tersebut dapat digunakan untuk memprediksi variabel dependen. Ghozali, (2010:127).

Uji simultan atau uji $\mathrm{F}$ adalah untuk menjawab hipotesis empat dan tujuh. Uji ini digunakan untuk mengetahui apakah seluruh variabel bebas (independent variable) secara simultan mempunyai pengaruh terhadap variabel terikat (dependent variable). Pengujian ini dilakukan dengan membandingkan nilai $F_{\text {hitung }}$ dengan $F_{\text {tabel }}$ pada derajat kesalahan 5\%. Apabila nilai $F_{\text {hitung }}>$ dari nilai $F_{\text {tabel}}$, maka beberapa variabel bebas (Indepedent) secara simultan atau bersama-sama memberikan pengaruh yang signifikan terhadap variabel terikat (Dependent). Namun sebaliknya apabila nilai $F_{\text {hitung }}<$ dari nilai $F_{\text {tabel, maka }}$ beberapa variabel bebasnya (Indepedent) secara simultan tidak memberikan pengaruh terhadap variabel terikatnya (Dependent).

Uji F dapat juga dilakukan dengan melihat nilai probabilitas alphanya, apabila alpha $<0.05$ berarti beberapa variable bebas(Indepedent) memberikan pengaruh signifikan terhadap variabel terikatnya (Dependent). Sebaliknya apabila apabila alpha $>0.05$ berarti beberapa variable bebas tidak memberikan pengaruh yang signifikan terhadap variabel terikatnya.

Kriteria pengujian hipotesis secara simultan pada tingkat signifikansi 0,05 (5\%) adalah sebagai berikut:

Apabila $\mathrm{F}_{\text {hitung }}>\mathrm{F}_{\text {tabel }}$ atau alpha $<0.05$, maka tolak $\mathrm{H}_{0}$ dan terima $\mathrm{H}_{1}$

Apabila $\mathrm{F}_{\text {hitung }}<\mathrm{F}_{\text {tabel }}$ atau alpha $>0.05$, maka terima $\mathrm{H}_{0}$ dan tolak $\mathrm{H}_{1}$

Dari hasil perhitungan dapat dilihat apakah Hipotesa dapat diterima atau ditolak.

\section{HASIL DAN PEMBAHASAN}

Analisis Jalur (Path Analisis). Sub-Struktur 1 Gaya Kepemimpinan Transformasional dan Pelatihan Terhadap Motivasi

Tabel 1. Matriks Korelasi Antar Variabel

\begin{tabular}{|c|c|c|c|}
\hline \multicolumn{4}{|c|}{ Correlations } \\
\hline & & X1_GY_KEPEMP & X2_PELATIHAN \\
\hline \multirow{3}{*}{$\begin{array}{l}\text { X1_GY_KEPEM } \\
\text { P }\end{array}$} & Pearson Correlation & 1 & $.306^{* *}$ \\
\hline & Sig. (2-tailed) & & .003 \\
\hline & $\mathrm{N}$ & 92 & 92 \\
\hline \multirow[t]{3}{*}{ X2_PELATIHAN } & Pearson Correlation & $.306^{* *}$ & 1 \\
\hline & Sig. (2-tailed) & .003 & \\
\hline & $\mathrm{N}$ & 92 & 92 \\
\hline
\end{tabular}


Tabel 2. Hasil Regresi Gaya Kepemimpinan Transformasional dan Pelatihan Terhadap Motivasi

Coefficients $^{\mathbf{a}}$

\begin{tabular}{|c|c|c|c|c|c|c|}
\hline \multirow{2}{*}{\multicolumn{2}{|c|}{ Model }} & \multicolumn{2}{|c|}{$\begin{array}{c}\text { Unstandardized } \\
\text { Coefficients }\end{array}$} & \multirow{2}{*}{$\begin{array}{c}\text { Standardized } \\
\text { Coefficients } \\
\text { Beta }\end{array}$} & \multirow[b]{2}{*}{$\mathrm{t}$} & \multirow[b]{2}{*}{ Sig. } \\
\hline & & B & Std. Error & & & \\
\hline \multirow[t]{3}{*}{1} & (Constant) & 44.397 & 5.750 & & 7.722 & .000 \\
\hline & X1_GY_KEPEMP & .091 & .081 & .114 & 1.121 & .265 \\
\hline & X2_PELATIHAN & .587 & .162 & .366 & 3.613 & .000 \\
\hline
\end{tabular}

a. Dependent Variable: Y_MOTIVASI

Pengaruh Gaya Kepemimpinan Transformasional Tehadap Motivasi. Adapun hasil pengujian untuk menjawab hipotesis Pertama yaitu besarnya pengaruh langsung dan tidak langsung $\mathrm{X}_{1}$ terhadap $\mathrm{Y}$.

Pengaruh langsung $\mathrm{X}_{1}$ terhadap $\mathrm{Y}$

$$
\begin{aligned}
\mathrm{X}_{1} \rightarrow \mathrm{Y} & =\mathrm{X}_{1} \quad \mathrm{Y} \\
& =\left(\mathrm{Pyx}_{1}\right)\left(\mathrm{Pyx}_{1}\right) \\
& =(0.144)(0.144) \\
& =0.020736=2,07 \%
\end{aligned}
$$

Pengaruh tidak langsung $\mathrm{X}_{1}$ terhadap $\mathrm{Y}$

$$
\begin{array}{ll}
\mathrm{X}_{1} \text { terhadap } \mathrm{Y} & =\mathrm{X}_{1} \quad \mathrm{X}_{2} \rightarrow \mathrm{Y} \\
\text { melalui } \mathrm{X}_{2} & =\left(\mathrm{Pyx}_{1}\right)\left(\mathrm{rx}_{1} \mathrm{X}_{2}\right)\left(\mathrm{Pyx}_{2}\right) \\
& =(0.144)(0.306)(0.366) \\
& =0.01612742=1,61 \%
\end{array}
$$

Total pengaruh langsung dan tidak langsung

$$
\begin{aligned}
& =0.020736+0.01612742 \\
& =0.03686342=3,68 \%
\end{aligned}
$$

Pengaruh Pelatihan Tehadap Motivasi. Adapun hasil pengujian untuk menjawab hipotesis Kedua yaitu besarnya pengaruh langsung dan tidak langsung $\mathrm{X}_{2}$ terhadap $\mathrm{Y}$.

Pengaruh langsung $\mathrm{X}_{2}$ terhadap $\mathrm{Y}$

$$
\begin{aligned}
\mathrm{X}_{2} \rightarrow \mathrm{Y} & =\mathrm{X}_{2} \mathrm{Y} \\
& =\left(\mathrm{Pyx}_{2}\right)\left(\mathrm{Pyx}_{2}\right) \\
& =(0.366)(0.366) \\
& =0.133956=13,39 \%
\end{aligned}
$$

Pengaruh tidak langsung $\mathrm{X}_{2}$ terhadap $\mathrm{Y}$

$$
\begin{array}{ll}
\mathrm{X}_{2} \text { terhadap } \mathrm{Y} & =\mathrm{X}_{2} \quad \mathrm{X}_{1} \rightarrow \mathrm{Y} \\
\text { melalui } \mathrm{X}_{1} & =\left(\mathrm{Pyx}_{2}\right)\left(\mathrm{rx}_{2} \mathrm{X}_{1}\right)\left(\mathrm{Pyx}_{1}\right) \\
& =(0.366)(0.306)(0.144) \\
& =0.01612742=1,61 \%
\end{array}
$$

Total pengaruh langsung dan tidak langsung

$$
\begin{aligned}
& =0.133956+0.01612742 \\
& =0.15008342=15 \%
\end{aligned}
$$


Tabel 3. Rekapitulasi Pengaruh Langsung dan Tidak Langsung Gaya Kepemimpinan Transformasional dan Pelatihan terhadap Motivasi

\begin{tabular}{|c|c|c|c|c|}
\hline \multirow{2}{*}{ Variabel } & \multirow{2}{*}{ Langsung } & \multicolumn{2}{|c|}{ Tidak Langsung } & \multirow[t]{2}{*}{ Sub Total } \\
\hline & & $\mathbf{X}_{1}$ & $\mathbf{X}_{2}$ & \\
\hline \multicolumn{5}{|l|}{ Gaya Kepemimpinan } \\
\hline Transformasional $\left(\mathrm{X}_{1}\right)$ & $2,07 \%$ & & $1,61 \%$ & $3,68 \%$ \\
\hline Pelatihan $\left(\mathrm{X}_{2}\right)$ & $13,39 \%$ & $1,61 \%$ & & $15 \%$ \\
\hline & $\begin{array}{l}\text { uh } X_{1}, X_{2} \\
\text { variabel lain }\end{array}$ & & & $\begin{array}{l}18,68 \% \\
81,32 \%\end{array}$ \\
\hline
\end{tabular}

Tabel 4.Uji R dan R Square

\begin{tabular}{llrrrr}
\multicolumn{9}{c}{ Model Summary } \\
\hline Model & R & R Square & $\begin{array}{c}\text { Adjusted R } \\
\text { Square }\end{array}$ & $\begin{array}{r}\text { Std. Error of } \\
\text { the Estimate }\end{array}$ \\
\hline 1 & $.415^{\mathrm{a}}$ & .172 & & .154 & 5.657 \\
\hline
\end{tabular}

a. Predictors: (Constant), X2_PELATIHAN,

X1_GY_KEPEMP

Nilai $\mathrm{R}$ sebesar 0,415 menunjukan korelasi ganda (Gaya Kepemimpinan Transformasional dan Pelatihan) dengan Motivasi. Dengan mempertimbangkan variasi Nilai R Square sebesar 0, 172 yang menunjukan kecilnya peran atau kontribusi variabel Gaya Kepemimpinan Transformasional dan Pelatihan mampu menjelaskan variabel Motivasi sebesar $17,2 \%$ dan sisanya $82,8 \%$ dipengaruhi oleh variabel-variabel lain.

Pengaruh Gaya Kepemimpinan Transformasional dan Pelatihan secara bersamasama terhadap Motivasi. Untuk menjawab tujuan ketiga mengenai pengaruh antara Gaya Kepemimpinan Transformasional dan Pelatihan secara bersama-sama tehadap Motivasi dapat dilihat pada hasil perhitungan dibawah ini:

Pengaruh langsung $\mathrm{X}_{1} \& \mathrm{X}_{2}$ terhadap $\mathrm{Y}$

$$
\begin{aligned}
\mathrm{X}_{1} \& \mathrm{X}_{2} \rightarrow \mathrm{Y} \quad= & \mathrm{X}_{1} \& \mathrm{X}_{2} \mathrm{Y} \\
& =(\mathrm{Pyx} 1 . \mathrm{Pyx} 1)+(\mathrm{Pyx} 2 . \mathrm{Pyx} 2) \\
& =2,07 \%+13,39 \% \\
& =15,46 \%
\end{aligned}
$$

Pengaruh tidak langsung secara bersama-sama antara $\mathrm{X}_{1} \& \mathrm{X}_{2}$ terhadap $\mathrm{Y}$

$$
\begin{aligned}
& =\mathrm{X} 1 \& \mathrm{X} 2 \rightarrow \mathrm{Y} \\
& =(\mathrm{Pyx} 1)(\mathrm{rx} 1 \mathrm{x} 2)(\mathrm{Pyx} 2)+(\mathrm{Pyx} 2)(\mathrm{rx} 1 \mathrm{x} 2)(\mathrm{Pyx} 1) \\
& =1,61 \%+1,61 \% \\
& =3,22 \%
\end{aligned}
$$

Total pengaruh langsung dan tidak langsung

$$
\begin{aligned}
& =3,68 \%+15 \% \\
& =18,68 \%
\end{aligned}
$$




\section{Sub-Struktur II Gaya Kepemimpinan Transformasional dan Pelatihan Terhadap Kinerja}

Tabel 5. Matriks Korelasi Antar Variabel Correlations

\begin{tabular}{llrr}
\hline \multicolumn{3}{c}{ Correlations } \\
\hline X1_GY_KEPEMP & X1_GY_KEPEMP & X2_PELATIHAN \\
& Pearson Correlation & 1 & $.306^{* *}$ \\
& Sig. (2-tailed) & & .003 \\
& $\mathrm{~N}$ & 92 & 92 \\
X2_PELATIHAN & Pearson Correlation & $.306^{* *}$ & 1 \\
& Sig. (2-tailed) & .003 & 92 \\
& $\mathrm{~N}$ & 92 & \\
\hline
\end{tabular}

**. Correlation is significant at the 0.01 level (2-tailed).

Sumber : Hasil Ouput SPSS 16.0 (2015)

Tabel 6. Hasil Regresi Gaya Kepemimpinan Transformasional dan Pelatihan

Terhadap Kinerja

Coefficients $^{\mathrm{a}}$

\begin{tabular}{|c|c|c|c|c|c|c|}
\hline & \multirow[b]{2}{*}{ Model } & \multicolumn{2}{|c|}{ Unstandardized Coefficients } & \multirow{2}{*}{$\begin{array}{c}\text { Standardized } \\
\text { Coefficients }\end{array}$} & \multirow[b]{2}{*}{$\mathrm{t}$} & \multirow[b]{2}{*}{ Sig. } \\
\hline & & $\mathrm{B}$ & Std. Error & & & \\
\hline \multirow[t]{3}{*}{1} & (Constant) & 21.811 & 3.039 & & 7.176 & .000 \\
\hline & $\underset{\mathrm{P}}{\mathrm{X} 1 \_G Y \text { KEPEM }}$ & .123 & .043 & .291 & 2.870 & .005 \\
\hline & X2_PELATIHAN & .181 & .086 & .214 & 2.108 & .038 \\
\hline
\end{tabular}

a. Dependent Variable: Z_KINERJA

Pengaruh Gaya Kepemimpinan Transformasional Terhadap Kinerja. Adapun hasil pengujian untuk menjawab hipotesis Keempat yaitu besarnya pengaruh langsung dan tidak langsung $\mathrm{X}_{1}$ terhadap $\mathrm{Z}$.

1. Pengaruh langsung $X_{1}$ terhadap $Z$

$$
\begin{aligned}
\mathrm{X}_{1} \rightarrow \mathrm{Z} & =\mathrm{X}_{1} \quad \mathrm{Z} \\
& =\left(\mathrm{Pzx}_{1}\right)\left(\mathrm{Pzx}_{1}\right) \\
& =(0.291)(0.291) \\
& =0.084681=8,46 \%
\end{aligned}
$$

2. Pengaruh tidak langsung $X_{1}$ terhadap $Z$

$$
\begin{array}{ll}
\mathrm{X}_{1} \text { terhadap } \mathrm{Z} & =\mathrm{X}_{1} \quad \mathrm{X}_{2} \rightarrow \mathrm{Z} \\
\text { melalui } \mathrm{X}_{2} & =\left(\mathrm{PzX}_{1}\right)\left(\mathrm{rx}_{1} \mathrm{X}_{2}\right)\left(\mathrm{PzX}_{2}\right) \\
& =(0.291)(0.306)(0.214) \\
& =0.01905584=1,90 \%
\end{array}
$$

3. Total pengaruh langsung dan tidak langsung

$$
\begin{aligned}
& =0.084681+0.01905584 \\
& =0.10373684=10,37 \%
\end{aligned}
$$


Pengaruh Pelatihan Tehadap Kinerja. Adapun hasil pengujian untuk menjawab hipotesis 5 (lima) yaitu besarnya pengaruh langsung dan tidak langsung $\mathrm{X}_{2}$ terhadap $\mathrm{Z}$.

4. Pengaruh langsung $X_{2}$ terhadap $Z$

$$
\begin{aligned}
\mathrm{X}_{2} \rightarrow \mathrm{Z} & =\mathrm{X}_{2} \quad \mathrm{Z} \\
& =\left(\mathrm{Pyx}_{2}\right)\left(\mathrm{Pyx}_{2}\right) \\
& =(0.214)(0.214) \\
& =0.045796=4,57 \%
\end{aligned}
$$

5. Pengaruh tidak langsung $X_{2}$ terhadap $Z$

$$
\begin{array}{ll}
\mathrm{X}_{2} \text { terhadap } \mathrm{Z} & =\mathrm{X}_{2} \quad \mathrm{X}_{1} \rightarrow \mathrm{Z} \\
\text { melalui } \mathrm{X}_{1} & =\left(\mathrm{Pyx}_{2}\right)\left(\mathrm{rx}_{2} \mathrm{X}_{1}\right)\left(\mathrm{Pyx}_{1}\right) \\
& =(0.214)(0.306)(0.291) \\
& =0.01905584=1,90 \%
\end{array}
$$

\begin{tabular}{|c|c|c|c|c|}
\hline \multicolumn{5}{|c|}{ Model Summary } \\
\hline Model & $\mathrm{R}$ & R Square & $\begin{array}{l}\text { Adjusted R } \\
\text { Square }\end{array}$ & $\begin{array}{l}\text { Std. Error of } \\
\text { the Estimate }\end{array}$ \\
\hline 1 & $.411^{\mathrm{a}}$ & .169 & .150 & 2.990 \\
\hline
\end{tabular}

6. Total pengaruh langsung dan tidak langsung

$$
\begin{aligned}
& =0.045796+0.01905584 \\
& =0.06485184=6,48 \%
\end{aligned}
$$

Tabel 7. Rekapitulasi Pengaruh Langsung dan Tidak Langsung Gaya Kepemimpinan Transformasional dan Pelatihan terhadap Kinerja

\begin{tabular}{crrrr}
\hline Variabel & \multirow{2}{*}{ Langsung } & \multicolumn{2}{c}{ Tidak Langsung } & Sub Total \\
& & $\mathbf{X}_{\mathbf{1}}$ & $\mathbf{X}_{\mathbf{2}}$ & \\
\hline Gaya Kepemimpinan & & & & \\
Transformasional $\left(\mathrm{X}_{1}\right)$ & $8,46 \%$ & & $1,90 \%$ & $10,36 \%$ \\
Pelatihan $\left(\mathrm{X}_{2}\right)$ & $4,57 \%$ & $1,90 \%$ & & $6,47 \%$ \\
& Pengaruh $\mathrm{X}_{1}, \mathrm{X}_{2}$ & & & $16,9 \%$ \\
\multicolumn{2}{r}{ Pengaruh variabel lain } & & $83,1 \%$ \\
\hline
\end{tabular}

Tabel 8. Uji R dan R Square

a. Predictors: (Constant), X2_PELATIHAN,

$$
\text { X1_GY_KEPEMP }
$$

Pengaruh Gaya Kepemimpinan Transformasional dan Pelatihan secara bersamasama terhadap Kinerja. Untuk menjawab tujuan Keenam mengenai pengaruh antara Gaya Kepemimpinan Transformasional dan Pelatihan secara bersama-sama tehadap Kinerja dapat dilihat pada hasil perhitungan dibawah ini:

7. Pengaruh langsung $X_{1} \& X_{2}$ terhadap $Z$

$$
\begin{aligned}
\mathrm{X}_{1} \& \mathrm{X}_{2} \rightarrow \mathrm{Z} & =\mathrm{X}_{1} \& \mathrm{X}_{2} \mathrm{Z} \\
& =(\operatorname{Pyx} 1 \cdot \mathrm{Pyx} 1)+(\operatorname{Pyx} 2 . \operatorname{Pyx} 2) \\
& =8,46 \%+4,57 \%
\end{aligned}
$$




$$
=13,03 \%
$$

8. Pengaruh tidak langsung secara bersama-sama antara $X_{1} \& X_{2}$ terhadap $Z$

$$
\begin{aligned}
& =\mathrm{X} 1 \& \mathrm{X} 2 \rightarrow \mathrm{Z} \\
& =(\mathrm{Pzx} 1)(\mathrm{rx} 1 \mathrm{x} 2)(\mathrm{Pzx} 2)+(\mathrm{Pzx} 2)(\mathrm{rx} 1 \mathrm{x} 2)(\mathrm{Pzx} 1) \\
& =1,90 \%+1,90 \% \\
& =3,8 \%
\end{aligned}
$$

9. Total pengaruh langsung dan tidak langsung

\begin{tabular}{|c|c|c|c|c|c|c|}
\hline \multirow[b]{2}{*}{ Model } & & \multicolumn{2}{|c|}{ Unstandardized Coefficients } & \multirow{2}{*}{$\begin{array}{c}\begin{array}{c}\text { Standardized } \\
\text { Coefficients }\end{array} \\
\text { Beta }\end{array}$} & \multirow[b]{2}{*}{$\mathrm{t}$} & \multirow[b]{2}{*}{ Sig. } \\
\hline & & $\mathrm{B}$ & Std. Error & & & \\
\hline \multirow[t]{2}{*}{1} & (Constant) & 4.557 & 2.803 & & 1.626 & .108 \\
\hline & Y_Motivasi & .342 & .049 & .591 & 6.948 & .000 \\
\hline
\end{tabular}

$$
\begin{aligned}
& =13,03 \%+3,8 \% \\
& =16,83 \%
\end{aligned}
$$

\section{Sub Struktur III Motivasi Terhadap Kinerja}

Tabel 9. Hasil Motivasi Terhadap Kinerja

Coefficients $^{\mathrm{a}}$

a. Dependent Variable: Z_Kinerja

Pengaruh Motivasi terhadap Kinerja. Untuk menjawab hipotesis Ketujuh untuk melihat besarnya pengaruh langsung variabel $\mathrm{Y}$ terhadap $\mathrm{Z}$ sebagai berikut:

10. Pengaruh langsung $Y$ terhadap $Z$

$$
\begin{aligned}
\mathrm{Y} \rightarrow \mathrm{Z} & =\text { Pzy. Pzy } \\
& =(0.591)(0.591) \\
& =0.349281 \\
& =34,92 \%
\end{aligned}
$$

Tabel 10. Uji R dan R Square

\section{Model Summary}

\begin{tabular}{lrrrr}
\hline Model & R & R Square & $\begin{array}{l}\text { Adjusted R } \\
\text { Square }\end{array}$ & $\begin{array}{l}\text { Std. Error of } \\
\text { the Estimate }\end{array}$ \\
\hline 1 & $.591^{\mathrm{a}}$ & .349 & .342 & 4.04397106 \\
\hline
\end{tabular}

a. Predictors: (Constant), Y_Motivasi 


\section{Hasil Uji Hipotesis}

Tabel 11. Hasil Uji Hipotesis

\begin{tabular}{|c|c|c|c|c|c|c|c|}
\hline No. & Hipotesis & t-test & f-test & alpha & t-tabel & f-tabel & Hasil \\
\hline 1. & $\begin{array}{c}\text { Gaya Kep } \\
\text { terhadap } \\
\text { Motivasi }\end{array}$ & 1,121 & - & 0,265 & 1,69 & - & $\begin{array}{c}\text { Tidak } \\
\text { berpengaruh } \\
\text { Signifikan }\end{array}$ \\
\hline 2. & $\begin{array}{l}\text { Pelatihan } \\
\text { terhadap } \\
\text { Motivasi }\end{array}$ & 3,613 & - & 0,000 & 1,69 & - & $\begin{array}{l}\text { Berpengaruh } \\
\text { Signifikan }\end{array}$ \\
\hline 3. & $\begin{array}{c}\text { Gaya Kep } \\
\text { melalui } \\
\text { Pelatihan } \\
\text { terhadap } \\
\text { Motivsi }\end{array}$ & - & 9,268 & 0,000 & - & 2,47 & $\begin{array}{l}\text { Berpengaruh } \\
\text { Signifikan }\end{array}$ \\
\hline 4. & $\begin{array}{c}\text { Gaya Kep } \\
\text { terhadap } \\
\text { Kinerja }\end{array}$ & 2,870 & - & 0,005 & 1,69 & - & $\begin{array}{l}\text { Berpengaruh } \\
\text { Signifikan }\end{array}$ \\
\hline 5. & $\begin{array}{c}\text { Pelatihan } \\
\text { terhadap } \\
\text { Kinerja }\end{array}$ & 2,108 & - & 0,038 & 1,69 & - & $\begin{array}{c}\text { Berpengaruh } \\
\text { Signifikan }\end{array}$ \\
\hline 6. & $\begin{array}{c}\text { Gaya Kep } \\
\text { melalui } \\
\text { Pelatihan } \\
\text { terhadap } \\
\text { Kinerja }\end{array}$ & - & 9,043 & 0,000 & - & 2,47 & $\begin{array}{l}\text { Berpengaruh } \\
\text { Signifikan }\end{array}$ \\
\hline 7. & $\begin{array}{c}\text { Motivasi } \\
\text { terhadap } \\
\text { Kinerja }\end{array}$ & 6,948 & - & 0,000 & 1,69 & - & $\begin{array}{l}\text { Berpengaruh } \\
\text { Signifikan }\end{array}$ \\
\hline
\end{tabular}

\section{PENUTUP}

Simpulan. Setelah dilakukan pengujian terhadap hipotesis, maka dapat disimpulkan sebagai berikut : (1). Gaya Kepemimpinan Transformasional tidak berpengaruh terhadap Motivasi. Dalam hal ini motivasi tenaga kependidikan Universitas Mercu Buana tidak dipengaruhi oleh Gaya Kepemimpinan Transformasional. Hal ini dikarenakan, responden yang bekerja di Universitas Mercu Buana memiliki sikap dan keyakinan dalam hal berinteraksi terhadap pimpinan didalam suatu organisasi yaitu mewajibkan untuk mentaati segala kebijakan yang telah ditetapkan oleh pimpinan selama tidak keluar dari koridor walaupun yang memimpin dalam suatu organisasi adalah seorang yang tidak dijadikan panutan atau role model oleh para pengikutnya dan tenaga kependidikan di Universitas Mercu Buana tetap akan termotivasi untuk menyelesaikan pekerjaan yang diberikan oleh pimpinan dengan sebaik-baiknya dengan terus mengembangkan potensi diri sehingga termotivasi juga untuk memberikan pendapat dan ide-ide yang membangun untuk melakukan evaluasi bagi organisasi. (2). Pelatihan berpengaruh secara signifikan dan positif terhadap Motivasi. Artinya variabel Pelatihan berpengaruh terhadap Motivasi. Dimana pengaruh secara langsung variabel pelatihan terhadap motivasi lebih besar pengaruhnya dibandingkan dengan pengaruh secara tidak langsung. (3). Gaya 
Kepemimpinan Transformasional dan Pelatihan secara bersama-sama berpengaruh secara signifikan dan positif terhadap Motivasi. Berdasarkan pengujian path analisis pengaruh langsung lebih besar nilainya dibanding dengan pengaruh tidak langsung. (4). Gaya Kepemimpinan Transformasional berpengaruh secara signifikan dan positif terhadap kinerja tenaga kependidikan di Universitas Mercu Buana, Hal ini dibuktikan bahwa pengaruh langsung lebih besar nilainya dibandingkan dengan pengaruh tidak langsung. (5). Pelatihan berpengaruh secara signifikan dan positif terhadap Kinerja. Dalam hal ini pelatihan yang dilakukan dapat meningkatkan keterampilan dan pengetahuan sehingga tenaga kependidikan memiliki kepercayaan diri dan memahami apa yang harus dicapai dalam melaksanakan pekerjaan dan meningkatkan kinerjanya. (6). Gaya Kepemimpinan Transformasional. dan Pelatihan secara bersama-sama berpengaruh secara signifikan dan positif terhadap Kinerja. Berdasarkan pengujian path analisis pengaruh langsung lebih besar nilainya dibandingkan dengan pengaruh tidak langsung. (7). Motivasi berpengaruh positif dan signifikan terhadap Kinerja. Artinya variabel Motivasi berpengaruh terhadap Kinerja tenaga kependidikan di Lingkungan Universitas Mercu Buana. Hal ini dapat dipahami karena tingkat motivasi tenaga kependidikan menunjukkan tingkat yang tinggi.

Saran. Dari hasil penelitian ini, beberapa rekomendasi yang dapat penulis sampaikan terkait dengan penelitian ini antara lain: (1). Untuk meningkatkan motivasi kerja, maka perlu dilakukan perencanaan dan mengatur strategi pelatihan yang diberikan baik untuk tenaga kependidikan baru maupun tenaga kependidikan lama sehingga memahami apa yang harus dicapai dalam melaksanakan pekerjaanya, agar pelatihan tersebut lebih tepat sasaran perlu dilakukannya mekanisme training need analysis terlebih dahulu sehingga pelaksanaan pelatihannya sesuai dengan apa yang dibutuhkan dan memberikan dampak terhadap kelompok kerja atau organisasi secara keseluruhan baik dari aspek tangible maupun intangible. (2). Lembaga atau pimpinan perlu memberikan pengakuan kepada setiap tenaga kependidikan, mengenahi betapa pentingnya peranan dan keberadaan mereka diorganisasi dengan diberikan kesempatan untuk mengembangkan diri dan potensi serta berperan aktif dalam melaksanakan pekerjaannya, sehingga tenaga kependidikan memiliki keleluasaan untuk melakukan inovasi dan mengembangkan ide-ide terbaik. (3). Perlunya diberikan apresiasi atau reward kepada tenaga kependidikan atas hasil pekerjaannya yang menunjukkan prestasi kerja, hal tersebut akan menumbuhkan perasaan tentang pentingnya peranan mereka disuatu organisasi dan juga memberdayakan pegawai dengan memberikan tugas dan tanggungjawab yang lebih besar, dengan demikian tenaga kependidikan termotivasi untuk terus meningkatkan pengetahuannya dalam hal penyelesaian pekerjaan. (4). Tanggapan responden terhadap variabel Motivasi kuesioner karyawan mendapatkan kesempatan untuk mengembangkan karirnya total skor terendah, terbukti bahwa seluruh tenaga kependidikan Universitas Mercu Buana belum semua mendapatkan kesempatan untuk mengembangkan karir sesuai dengan potensi masing-masing, maka organisasi perlu memberikan sosialisasi ke seluruh fakultas/unit. (5). Hasil-hasil dalam penelitian ini dan keterbatasan-keterbatasan yang ditemukan agar dapat dijadikan sumber ide dan masukan bagi pengembangan penelitian ini dimasa yang akan datang, maka perluasan yang disarankan dari penelitian ini antara lain adalah menambah jumlah responden dan menambah variabel idependen yang mempengaruhi motivasi kerja dalam meningkatkan kinerja tenaga kependidikan. Variabel yang disarankan sepertinya budaya organisasi, komitmen organisasi, dukungan organisasi, lingkungan kerja, kepuasan kerja dan lain sebagainya. 


\section{DAFTAR RUJUKAN}

Abdul Hammed Aamer Waheed, (2011) Employes Development and Its Affect ib Employes Performance A Conceptual Framework, Islamabad Pakistan.

Al Rasyid, Harun Kismantoroadji. (2004) Statistika Sosial. Bandung: Program Pasca Sarjana UNPAD.

A. Soegihartono. (2012) "Pengaruh Kepemimpinan dan Kepuasan Kerja Terhadap Kinerja dengan Mediasi Komitmen (di PT. Alam Kayu Sakti Semarang)", Jurnal Mitra Ekonomi dan Manajemen Bisnis, 3 (1): 113-140.

Andi Supangat. (2007) Statistika Dalam Kajian Deskriptif, Inferensi, dan Nonparametrik. Edisi Pertama. Jakarta: Kencana.

Ayuh, Nadia (2011) The Relationship Between Work Motivation and Job Statisfaction, Pakistan Business Review, July 2011.332-347.

Bagus Aristayudha, (2013) "Pengaruh Budaya Organisasi, Kepemimpinan, dan Motivasi terhadap kinerja karyawan pada PT. BPD Bali Cabang Renon”. Jurnal manajemen Universitas Udayana. 2 (7)

Bass et.al (2003), serta Humpherys (2002) kemampuan pemimpin transformasional mengubah sistem nilai bawahan demi mencapai tujuan.

Bambang Wahyudi. (2007) “Manajemen Sumber Daya Manusia”,Sulita, Bandung.

Captureasia (2009), Kinerja adalah suatu proses belajar mengenal sebuah wacana pengetahuan dan keterampilan yang ditunjukan untuk penerapan hasil belajar yang sesuai dengan tuntutan tertentu.

Dedi Afandi, (2013) Pengaruh Gaya Kepemimpinan dan Pelatihan, Motivasi terhadap Kinerja Pegawai pada Lembaga Pendidikan Islam Ibnu Hajar.

Dessler, Gary, (2004) Manajemen Sumber Daya Manusia. Jakarta: Indeks.

Ferdinan, Augusty, (2006) Stractural Equation Modelling dalam Penelitian Manajemen Badan Penerbitan Universitas Diponegoro.

Ghozali, Imam, (2010) Aplikasi Analisis Multivariate Dengan Program SPSS, Penerbit Undip, Semarang

Gidion Alfa Diana, (2013) Pengaruh komunikasi dan kompensasi terhadap kinerja karyawan yang dimediasi semnagat kerja karyawan. Jurnal manajemen Universitas Udayana. 2 (10)

Hasibuan, Malayu, S. P., (2008) Manajemen Sumber Daya Manusia, edisi Revisi, Penerbit : Bumi Aksara, Jakarta.

Harun, (2004) Methode of Succesive Intervals (MSI)

Hapzi Ali \& Nandan Limakrisna, (2013) "Metodologi Penelitian (Petunjuk Praktis untuk Pemecahan Masalah Bisnis, Penyusunan Skripsi”, Tesis dan Disertasi, ed.1 Cet.1 Yogyakarta : Deepublish.

Herzberg, Munandar, (2001) Motivasi kerja adalah sekelompok pendorong yang berasal baik dari dalam maupun dari luar individu untuk melakukan pekerjaan yang mengarah pada pemenuhan kebutuhan-kebutuhannya.

Haznil Zainal, Pengaruh Pelatihan dan Pengawasan Terhadap Kinerja Pegawai Dinas Koperasi dan UKM Provinsi Riau.

Humala, Rozig. (2014) "Kepemimpinan Transformasional dengan Komitmet Organisasi Karyawan”, Jurnal Ilmiah Psikologi Terapan, 2 (2) agustus: 232.

Hugihes, Gimmet dan Curphy. (2012) Ledership, New York. Mc. Graw Hill Companies, inc. 
I nyoman Sudharma, (2013) "Pengaruh kompensasi dan motivasi terhadap kepuasan dan kinerja karyawan pada hotel Bakung beach Kuta-Bali". Jurnal manajemen Universitas Udayana. 2 (11).

Indrianto dan Supomo. (2007) Metodologi Penelitian. Jakarta: Indeks

Jonathan, Sarwono. (2006) Metode Penelitian Kuantitatif dan Kualitatif. Yogyakarta: Graha ilmu.

Kartika E.W. Kaihatu TS (2011) "Analisis Pengaruh Motivasi Kerja Terhadap Kepuasan Kerja (Studi Kasua pada Karyawan Restoran di Pakuwon Food Festival Surabaya)". Jurnal Manajemen dan Kewirausahaan, 12 (1), Maret 2010. 100-112.

Khairul muslim, (2006) Pengaruh gaya kepemimpinan dan kepuasan kerja terhadap kinerja karyawan politeknik negeri Lhoksemauwe. Tesis. Universitas Sumatera Utara.

Laurie E.Paarlberg, (2010) Transformational Ledership and Public Service Motivation : Driving Individual and Organizational Performance, University of North Carolina Wilmington.

Marihot Tua Efendi Hariandja, (2005) Manajemen Sumber Daya Manusia. PT. Grasindo. Jakarta.

Mathis, Robert. L \& Jackson John. H, (2007) Manajemen Sumber Daya Manusia, Jilid 3, Salemba Empat, Jakarta.

Nawawi,Hadari. (2006) Metode Penelitian Bidang Sosial. Gajah Mada University

Nursiah, (2004) Pengaruh gaya kepemimpinan dan kepuasan kerja terhadap kinerja karyawan pada PT. Indosat Divisi Regional Barat Medan. Tesis . Universitas Sumatera Utara.

Riduwan. (2005) Metode dan Teknik Menyusun Tesis. Alfabeta: Bandung.

Rismawati, (2008) Pengaruh motivasi kerja dan budaya organisasi terhadap kinerja dosen politeknik Negeri Medan. Tesis. Universitas Sumatera Utara.

Rivai, Veithzal. (2004) Manajemen Sumber Daya Manusia untuk Perusahaan: dari Teori ke Praktik, Raja Grafindo Persada, Jakarta.

Robbin, (2007) Kepemimpinan transformasional yaitu pimimpin yang mencurahkan perhatiannya kepada persoalan-persoalan yang dihadapi oleh para pengikutnya dengan cara memberikan semangat dan dorongan untuk mencapai tujuan.

Ronupandojo dan Husnan. (2002) Gaya kepemimpinan adalah suatu pola tingkah laku yang dirancang untuk mengitegrasikan tujuan organisasi dengan tujuan individu untuk mencapai tujuan tertentu.

Sanjaya dan Lasmini. (2007) Pengaruh kompensasi, lingkungan kerja, penempatan dan kepemimpinan terhadap semangat dan kegairahan kerja pegawai di Politeknik Negeri Bali. Binus Jakarta.

Sugiyono (2010) Metode Penelitian Bisnis, CV. Alfabeta, Bandung.

Simamora, Henry, (2006) Manajemen Sumber Daya Manusia, edisi keempat, cetakan pertama, Yogyakarta: YKPN

Tika, Pabundu. (2006) Budaya Organisasi dan Peningkatan Kinerja Perusahaan. Jakarta:Bumi Aksara.

Uma Sekaran, (2006) Metodologi Penelitian untuk Bisnis, Edisi 4, Buku 1, Jakarta: Salemba Empat.

Universitas Mercu Buana Jakarta. (2004) Buku Rencana Strategis UMB 2014-2019.

Veithzal Rivai, (2004) Kepemimpinan dan Perilaku Organisasi PT. Raja Grafindo Persada, Jakarta. 
Wibowo, (2013) Manajemen Kinerja. Edisi ketiga PT. Rajgrafindo Persada, Jakarta.

Yuniarsih, Tjutju dan Suwatno.(2008) Manajemen Sumber Daya Manusia. Bandung: Alfa Beta. 